\title{
Norois
}

Environnement, aménagement, société

$199 \mid 2006 / 2$

Canada : immigration, espaces urbanisés, parcs nationaux, loisir patrimonial

\section{Andrew (C.), Graham (K.A.), Phillips (S.D.) (dir.) - Urban Affairs. Back on the Policy Agenda}

Canada, McGill-Queen's University Press, 2002, 400 p.

\section{Cynthia Ghorra-Gobin}

\section{(2) OpenEdition \\ Journals}

\section{Édition électronique}

URL : http://journals.openedition.org/norois/2000

DOI : $10.4000 /$ norois. 2000

ISBN : 978-2-7535-1547-5

ISSN : 1760-8546

Éditeur

Presses universitaires de Rennes

\section{Édition imprimée}

Date de publication : 1 juin 2006

Pagination : 92-93

ISBN : 978-2-7535-0332-8

ISSN : 0029-182X

Référence électronique

Cynthia Ghorra-Gobin, « Andrew (C.), Graham (K.A.), Phillips (S.D.) (dir.) - Urban Affairs. Back on the Policy Agenda ", Norois [En ligne], 199 | 2006/2, mis en ligne le 13 décembre 2006, consulté le 23 septembre 2020. URL : http://journals.openedition.org/norois/2000 ; DOI : https://doi.org/10.4000/ norois. 2000 
Andrew (Caroline), Graham (Katherine A.), Phillips (Susan D.) (dir.), Urban Affairs: Back on the Policy Agenda, McGill-Queen's University Press, 2002, 400 p. (ISBN 0-7735-2353-7)

Cet ouvrage collectif réunissant 23 auteurs est publié sous la direction de trois femmes politologues (dont deux sont respectivement doyennes des facultés de sciences sociales à l'université d'Ottawa et à l'université de Carleton) et qui par ailleurs se veut transdisciplinaire (incluant quelques géographes) se donne pour objectif de présenter les enjeux de l'urbain contemporain - même si l'analyse concerne principalement le contexte canadien. Les auteurs partent du principe que la municipalité - dont le rôle était autrefois limité à l'offre de services publics - assume aujourd'hui des responsabilités politiques. Il leur revient en effet de répondre aux besoins de populations de plus en plus diversifiées tout en participant à la dynamique économique, sociale et culturelle. Les quatre grands thèmes retenus pour l'analyse

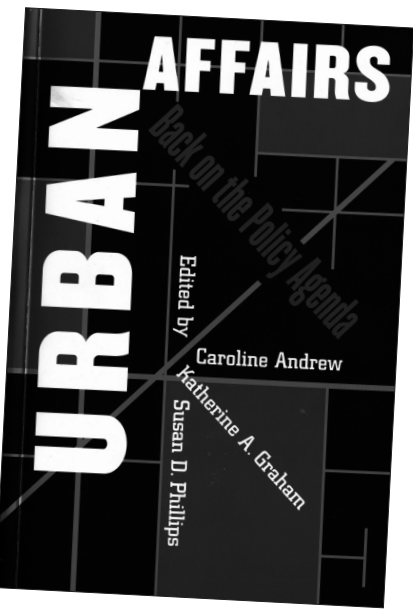
sont : la société civile, la gouvernance, le développement économique et les défis de la fiscalité locale. Les articles mettent ainsi en perspective les enjeux de la question urbaine, en raison des impacts de la mondialisation économique. Les notions de ville, région, nation ne sont plus jugées adéquates pour rendre compte de l'urbain et on en déduit la pertinence de l'échelle de la ville-région (city-region). Les relations entre les régions urbaines sont jugées complexes dans la mesure où elles participent des connections à l'économie globale via l'activité des entreprises transnationales. Certes les villes canadiennes ont un pouvoir limité (en raison du principe de leur soumission à la Province) mais parce qu'elles sont les lieux privilégiés du déploiement des mouvements sociaux, Elles devraient sérieusement intéresser l'État fédéral.

Le chapitre 1 rédigé par Valérie Preston et Madeleine Wong (respectivement professeurs de géographie à l'Université de York et à l'Université du Wisconsin - États-Unis) sur le thème de l'immigration retient l'attention du lecteur. La majorité des immigrés (plus exactement les trois quarts) qui s'installent au Canada se concentrent dans trois villes, Toronto, Vancouver et Montréal. La population immigrée est loin d'être homogène : on distingue les réfugiés (venus pour des raisons politiques), les riches investisseurs et ceux issus de la réunification familiale. De profonds changements continuent de structurer les flux migratoires. Après avoir attiré les Européens, le Canada attire désormais des populations de l'ensemble de la planète et notamment des pays asiatiques (57\% des flux migratoires). Par ailleurs compte tenu des avancées technologiques dans le domaine de la communication, il s'avère que les immigrés se présentent de plus en plus comme des « communautés transnationales » en raison des liens solides qu'ils maintiennent avec leur pays d'origine. Ce qui a pour conséquence de modifier sensiblement les notions de citoyenneté nationale et locale.

Cet ouvrage qui a priori rend compte des transformations en cours de la société urbaine canadienne - est extrêmement stimulant pour la réflexion urbaine. Aussi sa lecture devrait être vivement encouragée - y compris pour les non-spécialistes du Canada. 